\title{
Vermikülit Katkılı Sert Poliüretan ile Kaplanmış Ahşap Kompozitlerin Yüzey Sertliğinin, Yanma Davranışlarının ve Elektromanyetik Ekranlama Özelliklerinin İncelenmesi
}

\author{
Ali İhsan Kaya ${ }^{1}$, İbrahim Kırbaş ${ }^{2 *}$ \\ Ahmet Çifci ${ }^{3}$ \\ ${ }^{1}$ Burdur Mehmet Akif Ersoy Üniversitesi, Teknik Bilimler Meslek Yüksekokulu, Tasarım Bölümü, Burdur, Türkiye (ORCID: 0000-0002-1860-9610) \\ ${ }^{2}$ Burdur Mehmet Akif Ersoy Üniversitesi, Teknik Bilimler Meslek Yüksekokulu, Elektrik ve Enerji Bölümü, Burdur, Türkiye (ORCID: 0000-0002-5560-638X) \\ ${ }^{3}$ Burdur Mehmet Akif Ersoy Üniversitesi, Mühendislik-Mimarlık Fakültesi, Elektrik-Elektronik Mühendisliği Bölümü, Burdur, Türkiye (ORCID: 0000-0001-7679- \\ 9945)
}

(İlk Geliş Tarihi 4 Eylül 2019 ve Kabul Tarihi 27 Eylül 2019)

(DOI: 10.31590/ejosat.615661)

ATIF/REFERENCE: Kaya, A.İ., Kırbaş, İ., \& Çifci, A. (2019). Vermikülit Katkılı Sert Poliüretan ile Kaplanmış Ahşap Kompozitlerin Yüzey Sertliğinin, Yanma Davranışlarının ve Elektromanyetik Ekranlama Özelliklerinin İncelenmesi. Avrupa Bilim ve Teknoloji Dergisi, (17), 206-214.

$\ddot{O} \mathbf{z}$

Bu çalışmada mineral madde olarak 1sıl ve yalıtım amaçlı kullanıma sahip olan vermikülit, sert poliüretan malzemeye eklenerek iki ayrı ahşap kompozit malzemenin yüzey kaplamasında kullanılmıştır. Vermikülit toplam poliüretan kütlesine $\% 5$ ve $\% 10$ oranında eklenmiştir. Çalışmada ahşap kompozit malzeme olarak orta yoğunlukta lif levha (Medium Density Fiberboard - MDF) ve kontrplak (Plywood) kullanılmıştır. Sert poliüretan ile yüzeyleri kaplanan ahşap kompozit malzemelerin yanma davranış1 TS EN ISO 11925-2 standardına göre tek kaynaklı alev testi ile kütle kaybı ve 1sıl geçirgenlik değerleri DIN 4102 ve TS EN 13823 standardına göre incelenmiştir. Ayrıca malzemelerin yüzey sertlikleri ve elektromanyatik ekranlama özellikleri belirlenmiştir. Deneysel sonuçlara bakıldığında yüzeyi poliüretan ile kaplanmış ahşap kompozitlerde vermikülit katkısının her iki malzemenin yanma direncine olumlu katkı yaptığı belirlenmiştir. Yüzey sertliği kontraplak malzemlerde iyi sonuçlar verirken kütle kaybı ve ssıl geçirgenlik değerinin MDF malzemelerde daha iyi sonuçlar verdiği belirlenmiştir. Deneylerde ölçüm yapılan frekanslarda ağırlıkça katkılama oranı arttıkça elektromanyetik ekranlama özelliğinin artığı görülmüsstür.

\section{Investigation of Surface Hardness, Combustion Behavior and Electromagnetic Shielding Properties of Wood Composite Coated with Vermiculite-Doped Rigid Polyurethane}

\begin{abstract}
In this study, vermiculite, which is used as a mineral material for thermal and insulation purposes, was added to rigid polyurethane material and used in the surface coating of two different wood composite materials. Vermiculite was added to the total polyurethane
\end{abstract}

\footnotetext{
* Sorumlu Yazar: Burdur Mehmet Akif Ersoy Üniversitesi, Teknik Bilimler Meslek Yüksekokulu, Elektrik ve Enerji Bölümü, Burdur, Türkiye (ORCID: 0000-0002-5560-638X), ikirbas@mehmetakif.edu.tr
} 
mass by $5 \%$ and $10 \%$. In the study, medium density fiberboard (MDF) and plywood were used as wood composite materials. The combustion behavior of wood composite materials coated with rigid polyurethane was examined in accordance with TS EN ISO 11925 2 standard with single source flame test and mass loss and thermal permeability values according to DIN 4102 and TS en 13823 standard. In addition, surface hardness and electromagnetic shielding properties of the materials were determined. According to the experimental results, it was determined that vermiculite additive in wood composites whose surface is covered with polyurethane contributes positively to the combustion resistance of both materials. While surface hardness gives good results in plywood materials, it is determined that mass loss and thermal permeability values give better results in MDF materials. In the experiments, it has been observed that as the ratio of vermiculite at the measured frequencies increases, the electromagnetic shielding property also increases.

Keywords: Electromagnetic Shielding, Plywood, MDF, Polyurethane, Vermiculite, Combustion, Surface Hardness.

\section{Giriş}

Ahşap kompozit malzeme olan ve orta yoğunluklu lif levha olarak bilinen MDF (Medium Density Fiberboard) oldukça geniş bir kullanım alanına sahiptir. Çoğunlukla mobilya sektöründe kullanıldığı gibi inşaat, ulaşım gibi farklı kullanım alanlarına da sahiptir. (Özdemir ve Ayaz, 2017). Bilinen özellikleri ile masif ağaç malzemeye en iyi alternatif olmuştur. Ahşap malzemeye göre yoğunluğu yüksek, pürüzsüz bir yüzeye sahip olması ve ekonomik olması başlıca özellikleri arasındadır. Yüzeyi üzerine her çeşit lake, boya vernik ve kaplama yapılabilmektedir. Eğilme direnci, vida ve çivi tutma gücü yüksek olması artı bir avantaj sağlasa da, genel olarak ahşap kompozit malzemelerin özellikle MDF'nin yanma direncinin düşük olması en büyük dezavantajdır. Bu maksatla ahşap kompozit malzemelerin yanma özelliklerini iyileştirmek amaçlı bazı çalışmalar yapılmıştır. İstek ve ark., (2013) MDF yüzeyini çeşitli bor bileşikleri ile kaplanmış şekilde kullanımının yanma üzerine daha etkili olduğunu tespit etmişlerdir. Yine Özdemir ve Tutuş, (2016) yonga levha yüzeyinin borik asit ile kaplanmasıyla yanma davranışlarında olumlu etkiler belirlemişlerdir. Yanma özellikleri dışında yüzey özellikleri ile ilgili olarak yapılan bir çalışmada ise PVC kaplı panellerin darbe dayanımının daha iyi olduğunu, lake kaplı panellerin ise sigara yanı̆̆ı testinde daha iyi sonuç verdiğini belirlemişlerdir (İstek ve ark., 2016).

Kontrplak ince ağaç katmanlarının çeşitli yapıştırıcılar ile birleştirilmesiyle elde edilen ahşap kompozit malzemedir. Katmanların üst üste gelen kısımlarında lif yönleri birbirine dik olacak şekilde birleştirilir. Kontrplakların mekanik ve fiziksel özelliklerini kullanılan ağaç türü, tutkal, presleme süresi ve basıncı gibi etkenler belirler. Kullanılan ağaç türünün yoğunluğu yükseldikçe mekanik özellikler de daha iyi olmaktadır. Türkiye'de çoğunlukla kayın ve kavak türünden az miktar da çam ağacından kontrplak üretilmektedir (Bal ve ark., 2015). Kontrplakların mekanik özelliklerini belirlemeye yönelik yapılan çalışmada (Örs ve ark., 2002) kayın ve kavak kontrplakları yoğunluk, çekme-makaslama, eğilme direnci ve elastiklik modülü açısından incelemişlerdir. Kayın ağacından üretilen kontrplakların mekanik özelliklerinin kavak kontrplakların mekanik özelliklerinden daha iyi olduğunu belirlemişlerdir.

Poliol ile diizosiyanat bileşiğinin polikondenzasyon reaksiyonu sonucu oluşan yapıya poliüretan denilir. Poliüretan üretiminde Poliolün ve diizosiyonatın türüne ve miktarına göre fiziksel ve kimyasal özeliklerine etki etmek mümkündür. Değişik özeliklerde üretilen poliüretanlar inşaat, otomobil, yapıştırıcı, soğutma ve mobilya alanlarında sıklıkla kullanılmaktadır (Erdem ve ark., 2018; Seo et al., 2004). Kullanımının yoğun olduğu mobilya sektöründe sert poliüretan formunda tercih edilmektedir.

Vermikülit düşük maliyetli magnezyum alüminyum silikat mineralidir (Patro et al., 2008). Yüksek katyon değişimi ve adsorpsiyon kapasitesine sahiptir (Zang et al., 2016). Yüksek ısıya maruz kaldığında pul pul dökülür ve kurtçuklara benzer bir şekil alır ve hacmi genişler (Macheca et al., 2018; Binici, 2016). Genleşme sonucunda malzemenin yı̆̆ın yoğunluğu, yaklaşık $10 \mathrm{~kat}$ azalarak, $0.8 \mathrm{~g} / \mathrm{cm}^{3}$ 'ten $0.08 \mathrm{~g} / \mathrm{cm}^{3}$ 'e düşmektedir. Yığın yoğunluğundaki düşüş, vermikülitin kalitesine ve genleştirmenin yapıldığı firın performansına bağlı olmakta ve 1sıl işlem sonucunda yaklaşık 20 ila 30 katlık bir genleşme sağlanabilmektedir. Genleşmiş vermikülit ateşe dayanıklıdır $\left(1270-1370{ }^{\circ} \mathrm{C}\right)$ ve iyi bir 1sı $(0,028 \mathrm{~W} / \mathrm{mK})$ ve ses yalıtım özelliğine sahiptir. Bu özelliklerinden dolayı enerji verimli bina yapımında potansiyel bir adaydır. Mevcut durumda ise daha çok yapı ürünleri, bina izolasyonu, yangından korunma, otomotiv sektörü, çiçekçilik ve zirai uygulamalarda kullanılmaktadır. Sertliği 1.5-2.0 veya daha fazla, yoğunluğu 2.1-2.8, rengi amber, bronz, kahve, yeşil veya siyahtır. Özellikle 1slakken talka benzer. Vermikülit, biyotit ve flogopit ile yakından ilişkilidir. Başlıca farklılıkları vermikülit birim hücre tabakaları arasında su içermesine karşılık, biyotit potasyum içermektedir. 
Tablo 1'de dünyanın önemli vermikülit yataklarına ait vermikülit örneklerinin kimyasal bileşimleri verilmiştir.

Tablo 1. Bazı vermikülit yataklarının kimyasal bileşimleri (Esenli, 2012).

\begin{tabular}{lcccccc}
\hline $\begin{array}{c}\text { Bileşim } \\
-\%-\end{array}$ & $\begin{array}{c}\text { A.B.D. } \\
\text { Enoroe, } \\
\text { SCWR }\end{array}$ & $\begin{array}{c}\text { US } \\
\text { Louisa, } \\
\text { VA } \\
\text { Virginia }\end{array}$ & $\begin{array}{c}\text { G. Afrika } \\
\text { Palabora }\end{array}$ & $\begin{array}{c}\text { Brezilya, } \\
\text { Piaui } \\
\text { Eucatex }\end{array}$ & Türkiye & $\begin{array}{c}\text { Ağırlı̆g } \\
\text { göre } \\
\%\end{array}$ \\
\hline $\mathrm{SiO}_{2}$ & 38.66 & 38.34 & 39.37 & 45.10 & 38.64 & $38-46$ \\
$\mathrm{MgO}$ & 20.04 & 16.38 & 23.37 & 23.60 & 22.68 & $16-35$ \\
$\mathrm{Al}_{2} \mathrm{O}_{3}$ & 17.36 & 12.85 & 12.08 & 10.20 & 14.96 & $10-18$ \\
$\mathrm{Fe}_{2} \mathrm{O}_{3}$ & 8.45 & 8.80 & 5.45 & 5.80 & 9.29 & $5-10$ \\
$\mathrm{FeO}$ & --- & --- & 1.17 & - & --- & -- \\
$\mathrm{CaO}$ & 0.75 & 1.12 & 1.46 & 3.80 & 1.23 & $1-5$ \\
$\mathrm{TiO}_{2}$ & --- & 1.66 & 1.25 & 0.70 & --- & $1-3$ \\
$\mathrm{Cr}_{2} \mathrm{O}_{3}$ & 0.50 & 0.23 & --- & --- & -- \\
$\mathrm{Na}_{2} \mathrm{O}$ & --- & 1.72 & 0.80 & 0.10 & --- & --- \\
$\mathrm{Li}_{2} \mathrm{O}$ & --- & 0.01 & 0.03 & --- & --- & --- \\
$\mathrm{BaO}$ & 0.12 & ----- & -- & -- \\
$\mathrm{MnO}$ & 0.07 & 0.14 & 0.30 & 0.20 & --- & -- \\
$\mathrm{H}_{2} \mathrm{O}$ & 8.71 & 10.66 & 11.20 & 10.20 & 5.29 & $8-16$ \\
\hline
\end{tabular}

MTA verilerine göre Türkiye'de vermikülit yataklarının varlı̆̆ı fazla bilinmemekle birlikte jeolojik çalışmalar sırasında ofıyolit kuşaklarında vermikülit oluşumlarına rastlanmıştır. Şimdiye dek, saptanan en önemli vermikülit yatakları Sivas-Yıldızeli ve Malatya bölgelerindedir. Bunun dışında; Sivas-Gürün, Elazığ-Harput ve Kırşehir Keskin'de de küçük zuhurların varlı̆ı̆ ifade edilmektedir. Rezerv hesapları bu zuhurlarda 6-7 milyon ton muhtemel rezervin olduğunu göstermektedir. Sivas-Yıldızeli'ndeki vermikülit oluşumunun Türkiye'deki bilinen en büyük ve işletilen tek vermikülit yatağı olduğu ifade edilmektedir (Web_1).

Belirtildiği üzere ahşap malzemelerin fiziksel ve mekanik özelliklerini belirlemeye ve iyileştirme yönelik farklı çalışmalar yapılmıştır. Bir dezavantaj olarak görülen yanma özelliklerinin geliştirilmesi amaçlanan bu çalışmada vermikülit katkılı sert poliüretan malzeme ile MDF ve kontrplak ahşap kompozitlerin yüzeyi kaplanarak yanma, sertlik, elektromanyetik alan, kütle kayb1 ve 1sıl geçirgenlik özellikleri araştırılmıştır.

\section{Materyal ve Metot}

\subsection{Materyal}

MDF optimum yoğunluk, kusursuz yüzey yapısı, dengeli lif dağılımı ve mükemmel işleme özellikleri gibi bir çok özelliği birlikte taşıması mümkün olan ahşap malzemelerden birisidir. Bu nedenlerden ötürü MDF olarak TS EN 622-5 ahşap esaslı levhalar standardına uygun sertifika almış olan, AGT Ağaç Sanayi ve Tic. A.Ş. temin edilen ham MDF kullanılmıştır.

Kontrplağın fiziksel yapısı kalitesine ilişkin önemli ipuçları taşır. Ürün açısında ve gönyesinde olmalı, kalınlıkları tutarlı, katmanları düzgün, yüzeyi pürüzsüz olmalıdır. Kullanılan ağacın nem miktarı ideal olarak \%10 civarında olmalıdır. Nem miktarının fazla olması durumunda, kullanımda ve dış mekânlarda sorun çıkabilir. Tüm bu etkenlerde göz önünde bulundurularak ALUÇ Orman Ürünleri Pazarlama ve Tic. Ltd. Şti. firmasına ait kontrplak kullanılmıştır.

OSA Kimya tarafından üretilmiş ve Tablo 2'de özellikleri verilmiş polyol POL SENTA 77 ve izosiyonat olarak ta ISONAT 200 kullanılmıştır.

Tablo 2. Poliüretan bileşenine ait özellikler

\begin{tabular}{|l|l|c|c|}
\hline & Birim & POL SENTA 77 & ISONAT 200 \\
\hline Yoğunluk $/ 25^{\circ} \mathrm{C}$ & $\mathrm{g} / \mathrm{cm}^{3}$ & $1,00-1,15$ & $1,10-1,20$ \\
\hline Viskosite $/ 25^{\circ} \mathrm{C}$ & $\mathrm{mPas}$ & $350-450$ & $250-350$ \\
\hline Karışım oranı & Ağırlıkça & \multicolumn{2}{|c|}{$100: 100 \pm 2$} \\
\hline Krema zamanı $/ 22^{\circ} \mathrm{C}$ & $\mathrm{sn}$ & \multicolumn{2}{|c|}{$95-105$} \\
\hline Jelleşme zaman1 $/ 22{ }^{\circ} \mathrm{C}$ & $\mathrm{sn}$ & \multicolumn{2}{|c|}{$120-145$} \\
\hline Bitiş zamanı $/ 22^{\circ} \mathrm{C}$ & $\mathrm{sn}$ & 24 \\
\hline Tam kürleşme & saat & \multicolumn{2}{|c|}{} \\
\hline
\end{tabular}

Deneylerde kullanılan Vermikülit Sivas-Yıldızeli yöresinde, Organik Madencilik A.Ş.'den temin edilmiştir. Vermikülite ait fiziksel özellikler Tablo 3'de, kimyasal özellikler Tablo 4'de verilmiştir. 
European Journal of Science and Technology

Tablo 3. Vermikülite ait fiziksel özellikler

\begin{tabular}{|l|l|}
\hline Fiziksel durum & Kat1 \\
\hline Form & Aşındırıcı olmayan pullar \\
\hline Renk & Altın-gri-kahverengi \\
\hline pH (su bulamacında, $20^{\circ} \mathrm{C}$ ) & $7,0-9,0$ \\
\hline Erime sıcaklı̆̆ı & $1350^{\circ} \mathrm{C}$ \\
\hline Yoğunluğu (ham) & $\sim 800 \mathrm{~kg} / \mathrm{m}^{3}$ \\
\hline Yoğunluğu (pul pul) & $\sim 85 \mathrm{~kg} / \mathrm{m}^{3}$ \\
\hline Parçacık büyüklüğü (kaba) & $-12 /+2,8 \mathrm{~mm}$ \\
\hline Parçacık büyüklüğü (orta) & $-4 /+1,4 \mathrm{~mm}$ \\
\hline Parçacık büyüklüğü (ince) & $-2 /+0,71 \mathrm{~mm}$ \\
\hline Parçacık büyüklüğü (Süper ince) & $-1,0 /+0,355 \mathrm{~mm}$ \\
\hline
\end{tabular}

Tablo 4. Vermikülite ait kimyasal özellikler

\begin{tabular}{|c|c|c|c|c|c|c|c|c|c|}
\hline Bileşim & $\mathrm{SiO}_{2}$ & $\mathrm{MgO}$ & $\mathrm{Al}_{2} \mathrm{O}_{3}$ & $\mathrm{Fe}_{2} \mathrm{O}_{3}$ & $\mathrm{CaO}$ & $\mathrm{TiO}_{2}$ & $\mathrm{Na}_{2} \mathrm{O}$ & $\mathrm{K}_{2} \mathrm{O}$ & $\mathrm{P}_{2} \mathrm{O}_{5}$ \\
\hline$\%$ & 33,96 & 14,81 & 12,94 & 10,93 & 8,49 & 2,17 & 0,26 & 4,10 & 0,19 \\
\hline
\end{tabular}

Organik madencilik tarafından üretilen vermikülit, genleştirme işleminden sonra kaba, orta, ince ve süper ince olarak 4 farklı boyutta sınıflandırılmaktadır. Çalışmalarımızda süper ince boy vermikülit kullanılmıştır.

\subsection{Yöntem}

Ağırlıkça 1:1 oranında karıştırılan polyol ve diizosiyonatın tamamının ahşap kompozit malzemelerin yüzeyine dökülebilmesi için plastik bir silindir piston düzeneği kullanılmıştır. Ahşap kompozit malzemelerin etrafı Poli Vinil Clorür (PVC) malzeme ile kalıba alınmıştır. Kimyasalların belirli bir kremleşme zamanı ve reaksiyona girme zamanı vardır. Bu süreler dikkate alınarak üretimler yapılmıştır. Polyol ve diizosiyonatın piston silindir düzeneği içine alındıktan sonra $1500 \mathrm{~d} / \mathrm{dk}$ dönme hızında 40 sn kadar karıştırma işlemi yapılmıştır. Daha sonra 100 sn olan reaksiyon başlangıç süresi içinde daha önceden hazırlanmış kalıplara dökülerek üretim işlemi gerçekleşmiştir. Katkı malzemesi olan vermikülitin yapı içinde homojen bir şekilde dağılımının sağlanması önemlidir. Bunun için polyol üzerine diizosiyonat eklenmeden önce toplam kütlenin \%5 ağırlığınca vermikülit katkılandırıldı. 30 sn kadar karıştırma işlemi yapıldıktan sonra diizosiyonat eklenerek üretim gerçekleştirildi. Bu işlemler \%10 vermikülit katkılı poliüretan ve kontraplak malzeme için tekrarlanmıştır.

Ham, sert poliüretan kaplı ve vermikülit katkılı sert poliüretan kaplı malzemelerin üretim sonrası görüntüleri Şekil 1'de verilmiştir.

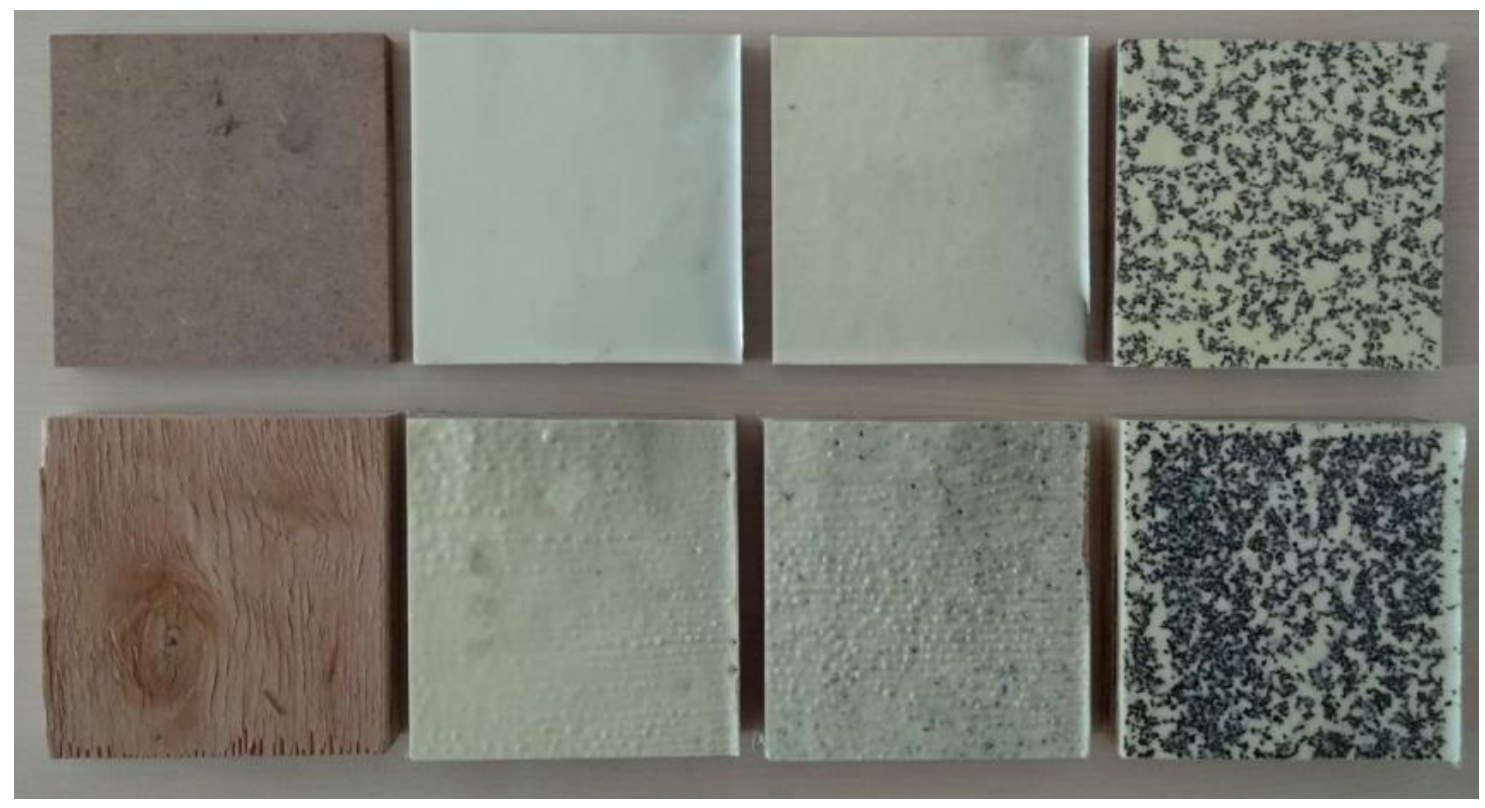

Şekil 1. Üretilen ahşap kompozit malzemeler

Mühendislik uygulamalarında çeşitli alanlarda kullanılan malzemelerin yanma ve alev hızlarını belirlenmesi gerekmektedir. Bu anlamda çeşitli tutuşma ve yanma testleri uygulanmaktadır (Tuzcu, 2010). Bu çalışmada üretilen sert poliüretan kaplı ahşap 
malzemelerin yanma ve tutuşma davranışlarının belirlenmesi için TSE EN ISO 11925-2 standardına göre tek kaynaklı alev testi uygulanmıştır. Bu standard düşey konumdaki deney numunelerinin sıfır ışıma etkisi altında doğrudan küçük bir aleve 15-30 sn maruz bırakılmak suretiyle yapı mamullerinin yanabilirliğinin tayini için uygulanan bir yöntemi kapsar. (Web_2). Yanma testi cihazı Şekil 2'de görülmektedir.

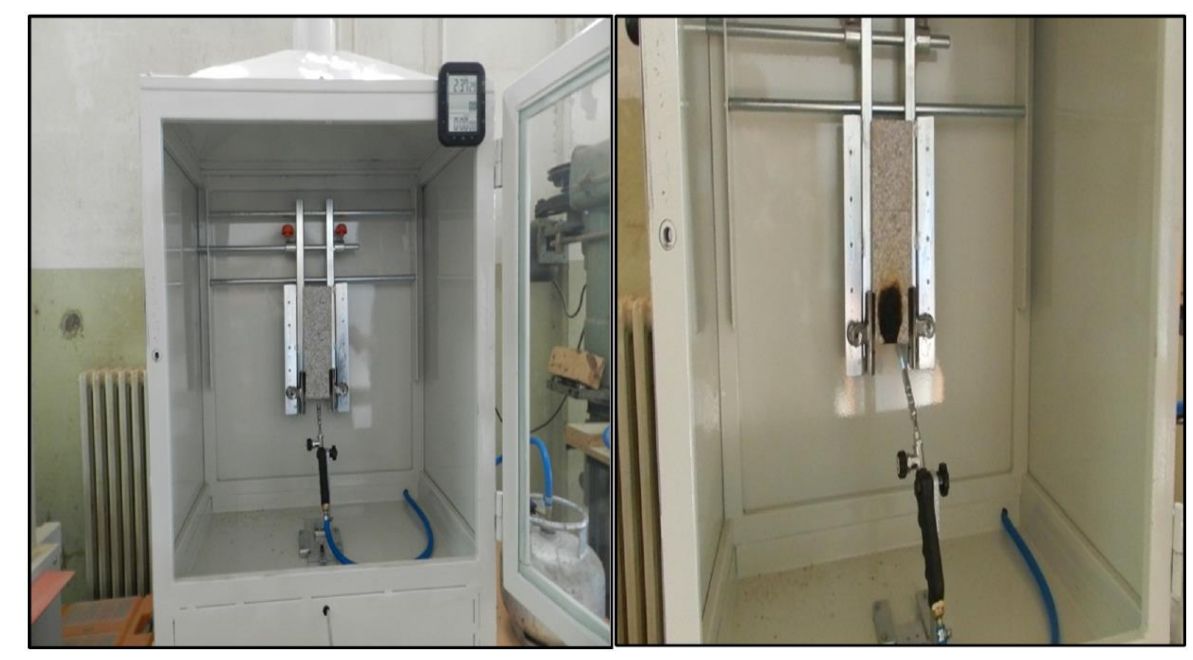

Şekil 2. Tek alev kaynakl yanma testi cihazı

Sertlik ölçümünde TSE EN 1534 standardı kullanılmış olup, Brinell sertliği $10 \mathrm{~mm}$ çaplı bilye, 3000 kg yükle 30 saniye süre ile malzeme üzerine bastırılır. Kuvvet, küresel yüzey alanına bölünerek Brinell sertlik değerleri tespit edilir (Heräjärvi, 2004; Ramesh et al., 2015). Bu çalı̧̧mada vermikülit katkılı poliüretan kaplı ahşap malzemelerin yüzey sertlik değerleri Misawa Seiki Marka sertlik ölçüm cihazı ile belirlenmiştir. Sertlik ölçme cihazı Şekil 3’te görülmektedir. Elektromanyetik alan ölçümleri ise $100 \mathrm{kHz}-6 \mathrm{GHz}$ arlığında ölçüm yapan Rohde\&Schwarz Spectrum Analyzer ile yapılmış olup ölçüm cihazı Şekil 4'te görülmektedir.

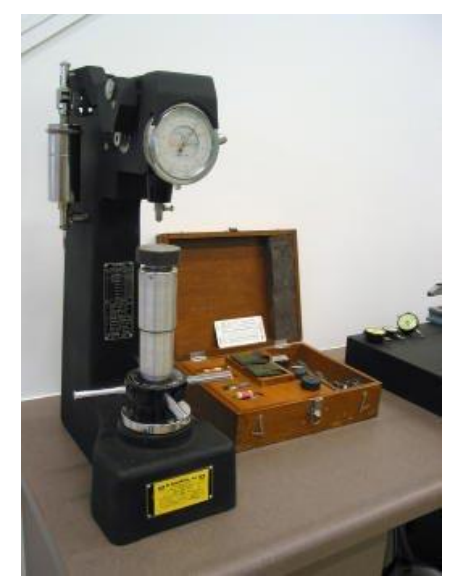

Şekil 3. Sertlik ölçme cihazı

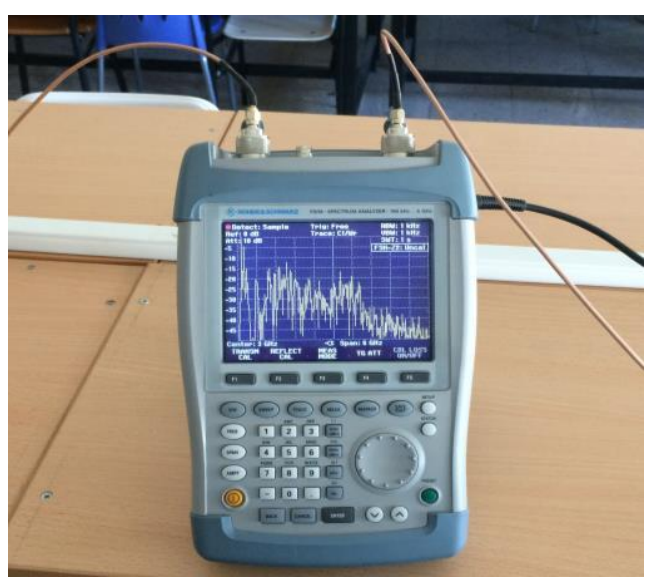

Şekil 4. Elektromanyetik ekranlama etkinliği ölçüm cihazı

Kütle kaybı ve 1Sı geçirgenlik oranlarının belirlenmesi amacı ile alev kaynağı, numune tutma aparatı ve kızılötesi lazer termometreden oluşan Şekil 5'te görülen deney düzeneği kullanılmıştır. Deney numuneleri $10 \mathrm{~cm}$ x $10 \mathrm{~cm}$ boyutlarında hazırlanmıştır. Toplam deney süresi 300 saniyedir. Deney süresi boyunca numunelerin arka yüzeyinin sıcaklığı 30 saniyelik periyotlarla kızılötesi lazer termometre ile ölçülerek kayıt altına alınmıştır. Aynı zamanda numunelerin yanma süresinde yanma olayından ne kadar etkilendiklerini ve kütle kaybını \% olarak belirlemek amacıyla ilk ağırlıkları ve son ağırlıkları tartılmış, yanma derinliği ve yanma çapı değerleri tespit edilmiştir. 


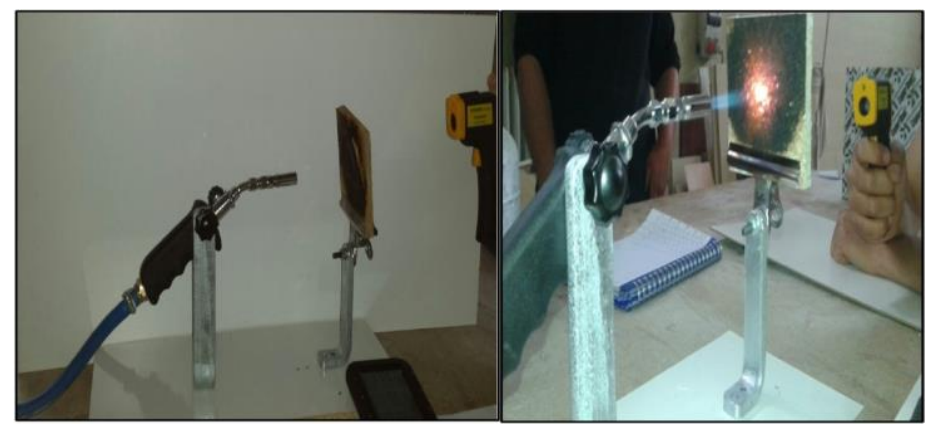

Şekil 5. Kütle kaybı ve ısı geçirgenlik test düzeneği

\section{Araştırma Sonuçları ve Tartışma}

Üretimi gerçekleştirilen numunelerin deney sonuçlarının açıklanması daha kolay olması bakımından Tablo 5'deki şekilde isimlendirilmesi yapılmıştır.

Tablo 5. Hazırlanmış numunelerin isimlendirilmesi

\begin{tabular}{|c|c|c|c|}
\hline Kisaltma & Açıklama & Kisaltma & Açıklama \\
\hline M0 & Ham MDF & K0 & Ham Kontrplak \\
\hline M1 & Yüzeyi sert poliüretan kaplı MDF & K1 & Yüzeyi sert poliüretan kaplı Kontrplak \\
\hline M2 & $\begin{array}{llll}\begin{array}{l}\text { Yüzeyi } \% 5 \\
\text { poliüretan kaplı MDF }\end{array} & \text { vermikülit } & \text { katkılı sert } \\
\end{array}$ & K2 & 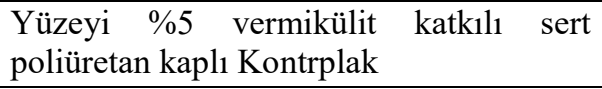 \\
\hline M3 & $\begin{array}{l}\text { Yüzeyi } \% 10 \text { vermikülit katkılı sert } \\
\text { poliüretan kaplı MDF }\end{array}$ & K3 & $\begin{array}{l}\text { Yüzeyi } \% 10 \text { vermikülit } \text { katkılı sert } \\
\text { poliüretan kaplı Kontrplak }\end{array}$ \\
\hline
\end{tabular}

\subsection{Yanma Direncinin Belirlenmesi}

Hazırlanan numuneler yanma testine tabi tutmadan önce $9 \mathrm{~cm} \times 25 \mathrm{~cm}$ boyutlarında kesilmiştir. Yapı malzemelerinin aleve doğrudan maruz kaldığında yangın dayanımlarının belirlenmesinde kullanılmakta olan TSE EN ISO 11925-2 standardında yapılan yanma testi sonucunda ahşap kompozit malzemelerin yanma davranışları Şekil 6'te görülmektedir. Şekil 6'ya göre malzemelerin tamamında alevin $150 \mathrm{~mm}$ çizgisine ulaşmadığı görülmektedir. Bu sonuca göre malzemenin DIN 4102 standardına göre yangına tepki sınıfı B2 (Normal alevlenir malzeme) olarak kabul edilmektedir.
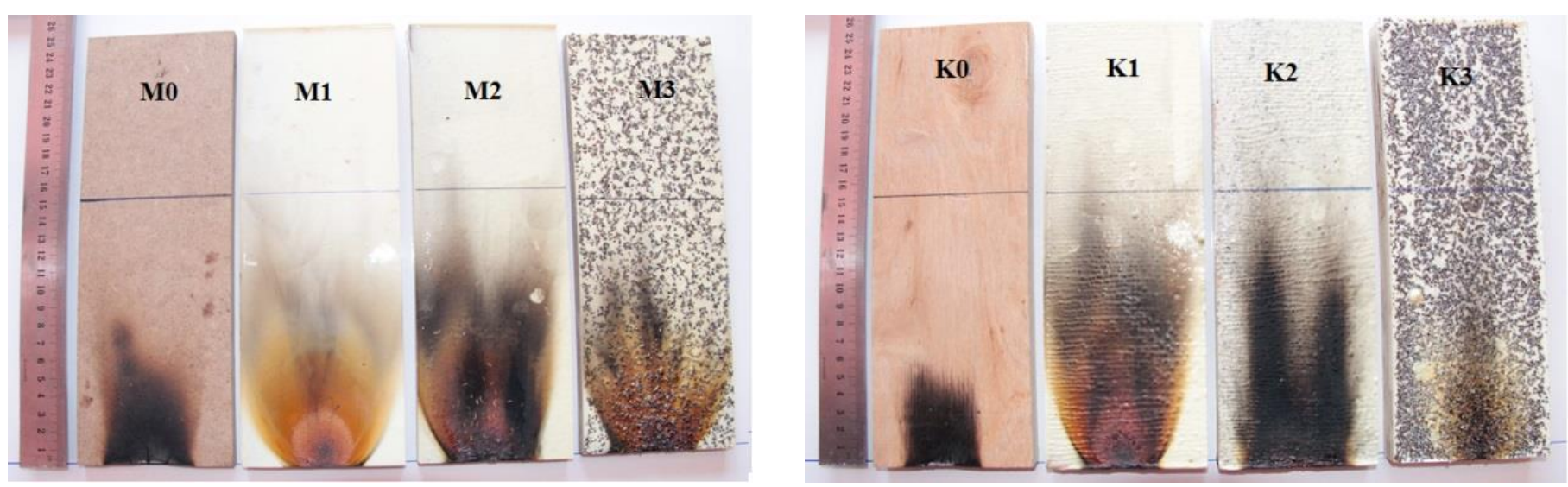

Şekil 6. Ahşap kompozit malzemelerin tek alev kaynakll yanma testi

\subsection{Sertlik Değerinin Belirlenmesi}

Sertlik ölçme genellikle, konik veya küresel standard bir ucun malzemeye batırılmasına karşı malzemenin gösterdiği direnci ölçmekten ibarettir. Uygun olarak seçilen sert uç, tatbik edilen bir yük altında malzemeye batırıldığında malzeme üzerinde bir iz bırakacaktır. Genel deyimle malzemenin sertliği, bu izin büyüklüğü ile ters orantılıdır (Yüksel, 2003). $10 \mathrm{~cm}$ x $10 \mathrm{~cm}$ boyutlarında kesilen numunelerin yüzey sertlik değerleri Misawa Seiki Marka sertlik ölçüm cihazı ile Brinell cinsinden belirlendi. Bu değerler sertlik ölçüm cihazı üzerinde bulunan dönüşüm tablosu kullanılarak Rockwell sertlik değerlerine dönüştürülmüştür. Elde edilen Brinell ve Rockwell sertlik değerleri Tablo 6'da verilmiştir. Malzemelerin yüzeyine poliüretan kaplama malzemenin katkılanması sertlik değerini artırmıştır. Vermikülit katkılı poliüretan ile kaplanmış malzemelere bakıldığında katkılama ile kontrplak malzemelerin sertlik değeri artarken MDF kaplı malzemelerin sertlik değerleri azalmıştır. ve Rockwell cinsinden 
Tablo 6. Sertlik değgrleri

\begin{tabular}{|l|c|c|l|c|c|}
\hline & ROCKWELL & BRINELL & & ROCKWELL & BRINELL \\
\hline M0 & 25 & 55 & K0 & 4 & 34 \\
\hline M1 & 62 & 92 & K1 & 8 & 38 \\
\hline M2 & 20 & 50 & K2 & 11 & 41 \\
\hline M3 & 20 & 50 & K3 & 16 & 46 \\
\hline
\end{tabular}

\subsection{Elektromanyetik Ekranlama}

Çeşitli iletken bileşikler ile işlem gören ahşap kompozit malzemeler yüksek ekranlama özelliği ve kolay endüstrileşme özelliği nedeniyle yaygın kullanıma uygundurlar. Teknolojik gelişmeler ile birlikte artan elektromanyetik kirlilik insan sağlığını tehdit etmektedir. Elektromanyetik alana uzun süre maruz kalındığında dokulara zarar vermekte ve zamanla kansere sebep olmaktadır (Zamanian ve Hardiman, 2005; Keangin et al., 2013). Elektromanyetik alanın istenmeyen zararlarından korunmak zorunluluk haline gelmiş̧ir. Şekil 7'de çalışmada kullanılan elektromanyetik ekranlama deney düzeneği gösterilmiştir.

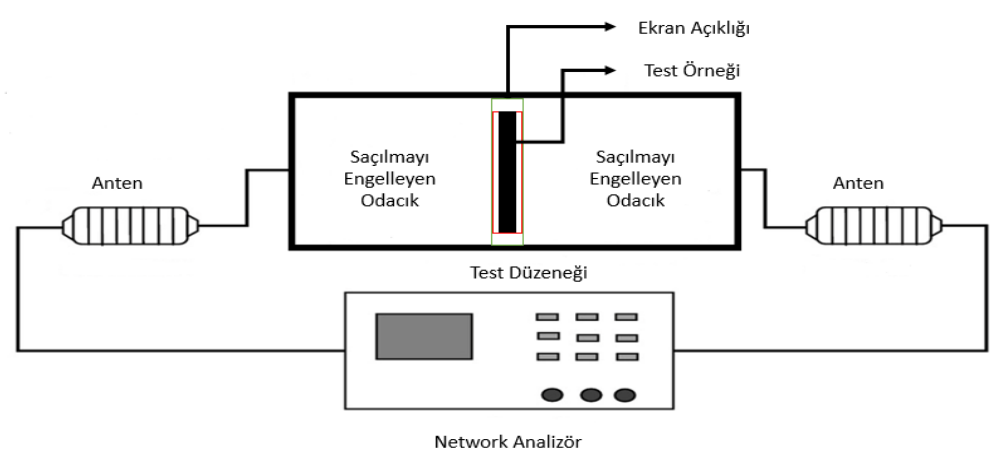

Şekil 7. Elektromanyetik ekranlama için şematik deney düzeneği

Deneylerde 3,4 cm x 7,2 cm boyutlarında numune kullanılmıştır. Şekil 8'de ölçüm sonuçları verilmiş̧ir.
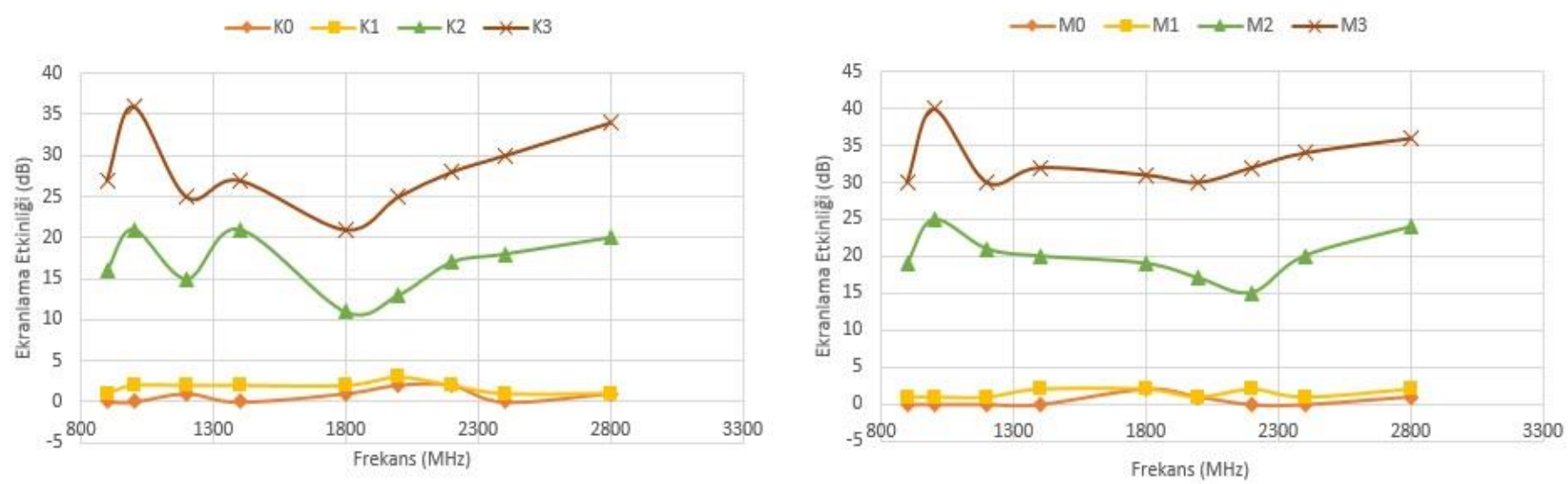

Şekil 8. Elektromanyetik ekranlama etkinliği ölçüm sonuçları

Elektromanyetik ekranlama etkinliği ölçüm sonuçları sonucunda bulunan bulgular maddeler halinde aşağıda verilmiştir:

- Yapılan deneylerde katkılanan maddelerin ekranlamaya olumlu etkisi olduğu tespit edilmiştir. Deneylerde ölçüm yapılan frekanslarda ağırlıkça katkılama oranı arttıkça ekranlama özelliği artığı görülmüştür.

- Bu sonuç malzemenin ekranlama performansının, o malzemenin iletkenliği ile doğrudan ilgili olduğunu ortaya koymaktadır. Sonuç olarak malzeme iletkenliği arttıkça ekranlama artar.

- Elektromanyetik alan ölçümleri sonucunda M3 malzemesinin ekranlama etkinliği standartlar dâhilinde bulunmuştur. K3 malzemesi ise $900 \mathrm{MHz}$ 'de ve $2400-2800 \mathrm{MHz}$ aralığında standartlar dâhilinde ekranlama yapmışıtır.

- Etkin ekranlama değeri $30 \mathrm{~dB}$ ve üzeri olması gerekip, M3 ve K3 dışındaki ahşap kompozit malzemelerin elektromanyetik ekranlama etkinliği Uluslararası İyonize Olmayan Radyasyondan Korunma Komisyonu (International Commission on NonIonizing Radiation Protection - ICNIRP) standartlarına göre vasat ekranlama olarak tespit edilmiştir.

\subsection{Kütle Kaybı ve Isı Geçirgenlik}

Yanma senaryolarından alev içinde kalmış bir malzemenin yanma davranışını araştırabilmek amacıyla DIN 4102 ve TS EN 13823 standardına göre dikey konumlandırılmış bir malzeme $20 \mathrm{~mm}$ mesafeden doğrudan aleve maruz bırakılmaktadır. Deney süresi $300 \mathrm{sn}$ 'de sinırlandırılmıştır. 300 sn deney süresi boyunca her 30 sn'de numunenin ön ve arka yüzeyinde oluşan sicaklık değerleri ölçülmüştür. 10 
$\mathrm{cm}$ x10 cm boyutlarındaki numeneler deneye başlamadan önce ve deney sonrası tartılarak kütle kaybı değerleri \% olarak belirlenmiştir. Zamana bağlı olarak arka yüzeye aktarılan sıcaklık derecesi ve kütle kaybı Tablo 7'de belirtilmiştir. Ayrıca deney sonrası numune yüzeyinde oluşan değiş̧iklikler (yanma çapı, yanma derinliği, kül oluşumu) gözlenmiş ve vermikülit katkılı poliüretan kaplı ahşap kompozit malzemeler de oluşan değişiklikler Şekil 9'da belirtilmiştir.

Tablo 6. Ahşap kompozit malzemelerin kütle kaybı ve ısı geçirgenlik değerleri

\begin{tabular}{|c|c|c|c|c|c|c|c|c|}
\hline \multirow{2}{*}{$\begin{array}{c}\text { Yanma süresi } \\
(\text { sn) }\end{array}$} & \multicolumn{8}{|c|}{ Arka yüzey sıcaklığı $\left({ }^{\circ} \mathrm{C}\right)$} \\
\hline & M0 & M1 & M2 & M3 & K0 & K1 & $\mathbf{K 2}$ & K3 \\
\hline $\mathbf{0}$ & 18,8 & 18,0 & 19,0 & 20,0 & 21,3 & 21,4 & 21,3 & 21,0 \\
\hline 30 & 24,9 & 21,3 & 22,6 & 21,3 & 21,3 & 25,0 & 23,4 & 20,8 \\
\hline 60 & 35,3 & 31,0 & 32,6 & 24,1 & 23,2 & 26,0 & 24,4 & 23,1 \\
\hline 90 & 69,2 & 89,0 & 54,7 & 33,0 & 23,7 & 27,3 & 30,7 & 25,7 \\
\hline 120 & 76,6 & 89,3 & 77,0 & 53,1 & 25,5 & 26,3 & 27,1 & 25,5 \\
\hline 150 & 81,9 & 93,8 & 82,0 & 78,0 & 27,7 & 26,2 & 27,4 & 32,0 \\
\hline 180 & 78,9 & 93,4 & 90,1 & 80,0 & 31,3 & 26,9 & 32,0 & 29,0 \\
\hline 210 & 80,6 & 91,7 & 89,7 & 83,0 & 36,9 & 30,0 & 36,0 & 27,7 \\
\hline 240 & 86,0 & 96,3 & 85,2 & 82,6 & 43,8 & 36,0 & 40,0 & 31,5 \\
\hline 270 & 104,0 & 97,5 & 77,6 & 83,0 & 50,3 & 36,1 & 45,0 & 34,0 \\
\hline 300 & 170,0 & 109,8 & 90,0 & 77,4 & 55,8 & 38,0 & 45,9 & 42,0 \\
\hline $\begin{array}{c}\text { Ön yüzey sıcaklığı ort. } \\
\left({ }^{\circ} \mathrm{C}\right)\end{array}$ & 290 & 265 & 270 & 257 & 313 & 362 & 317 & 262 \\
\hline $\begin{array}{c}\text { İlk ağırlık } \\
\text { (gr) }\end{array}$ & 59,13 & 71,54 & 66,35 & 74,93 & 74,87 & 92,30 & 82,85 & 99,81 \\
\hline $\begin{array}{c}\text { Son ağırlık } \\
\text { (gr) }\end{array}$ & 36,63 & 53,51 & 52,91 & 60,17 & 62,70 & 76,84 & 70,53 & 83,00 \\
\hline $\begin{array}{c}\text { Kütle kaybı } \\
(\%)\end{array}$ & 38,05 & 25,20 & 20,26 & 19,70 & 16,25 & 16,75 & 14,87 & 16,84 \\
\hline
\end{tabular}

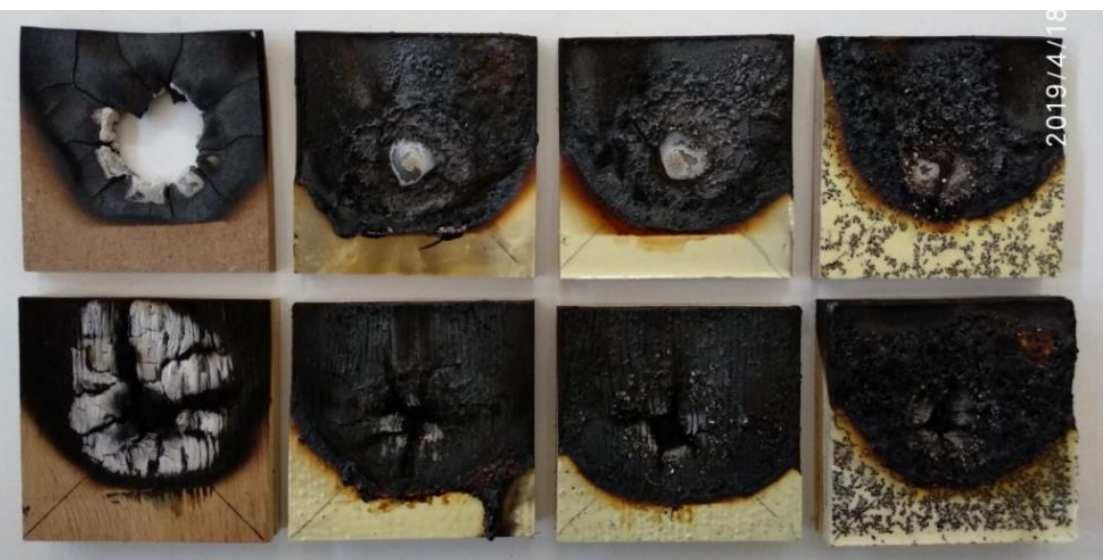

Şekil 9. Vermikülit katkılı poliüretan kaplı ahşap kompozit malzemelerin yanma davranışları

\section{Sonuç}

Sonuç olarak ahşap malzemelerin yanma, çizilme ve bazı fiziksel özelliklerinin iyileştirilmesi için vermikülit katkılı sert poliüretan kaplanması yapılan bu çalışmada;

- Hem MDF hem de kontrplak malzemelerin yanma dirençlerinde iyileşmeler tespit edilmiştir.

- Yüzeye kaplanan malzemelerin sertlik değerleri saf poliüretan kaplamaya oranla kontrplak malzemelere yapılan kaplamalarda artarken MDF yüzeyine yapılan kaplamalarda azalmıştır.

- Elektromanyetik ekranlama ölçüm değerlerinin, ham malzemelere oranla daha olumlu yönde bir iyileştirme yaptığı tespit edilmiştir. M3 ve K3 dışındaki malzemelerin elektromanyetik ekranlama performansı vasat ekranlama olarak tespit edilmiştir.

- Kütle kaybı incelendiğinde M0 malzemede \%38,05 iken M3 malzemede \%19,70 oranındadır. Sonuç olarak \%19 gibi bir iyileşme sağlanmıştır.

- Isıl geçirgenlik değerleri incelendiğinde M0 malzemede arka yüzey sıcaklığı maksimum $170{ }^{\circ} \mathrm{C}$ değerine ulaşmışken M3 malzemede maksimum $77,4^{\circ} \mathrm{C}$ değerinde kalmıştır. 
- Vermikülit katkılamanın kütle kabı ve 1sıl geçirgenlik bakımından kontrplak malzemelerde istenilen özelliklere olumlu katkı sağlamadığı belirlenmiştir.

\section{Kaynakça}

A.D. Macheca, W.W. Focke, M. Kaci, B. Panampilly, R. Androsch, "Flame Retarding Polyamide 11 With Exfoliated Vermiculite Nanoflakes", Polymer Engineering And Sclence, 1746-1755, 2018. DOI 10.1002/pen.24775

A. İstek, D. Aydemir, H. Eroğlu, "Combustion Properties of Medium-density Fiberboards Coated by a Mixture of Calcite and Various Fire Retardants", Turkish Journal of Agriculture and Forestry 37(5): 642-648, 2013.

A. İstek, K. Muğla, S.M. Onat, “The Effects of Different Overlays on the Surface Properties of MDF Panels”, Journal of Bartın Faculty of forestry, 18(2):121-125, 2016. DOI: 10.24011/barofd.267303

A., Zamanian, C., Hardiman, "Electromagnetic Radiation and Human Health: A Review of Sources and Effects", High Frequency Electronics, 4(3): 16-26, 2005.

B.C. Bal, Z. Gündeş, E. Akçakaya, "Kavak, Kayın ve Okaliptüs Kaplamaları ile Üretilen Kontrplakların Vida Tutma Direncinin Araştırılması", KSU Mühendislik Bilimleri Dergisi, 18(2):77-83, 2015.

F. Özdemir, A. Ayaz, "Investigation of the Effect on Combustion Resistance of Ammonium Polyphosphate and Boric Acid Chemicals Added to Surface Coating", Kastamonu Uni., Orman Fakültesi Dergisi, 17 (2): 290-297, 2017. Doi: 10.17475/kastorman.310967

F. Özdemir, A. Tutuş, "Effects of Coating with Calcite Togetter with Various Fire Retardants of on the Fire Properties of Particleboard", BioResources, 11 (3):6407-6415, 2016.

H. Binici, "Atık Mukavva, Alçı, Pomza, Perlit, Vermikülit ve Zeolit ile Yapılan Kompozitlerin Yangın Direncinin Araştırılması", Çukurova Üniversitesi Mühendislik Mimarlık Fakültesi Dergisi, 31(1):1-10, 2016.

H. Heräjärvi, "Variation of Basic Density and Brinell Hardness within Mature Finnish Betula Pendula and B. Pubescens Stems", Wood and Fiber Science, 36(2):216-227, 2004.

H. Tuzcu, "Isı Yalıtımı ve Otomotiv Endüstrilerinde Kullanılan Yanmaya Dirençli Poliüretan Esaslı Malzemelerin Tutuşma ve Yanma Karakteristiklerinin Deneysel İncelenmesi” Pamukkale Üniversitesi Fen Bilimleri Enstitüsü Yüksek Lisans Tezi, 31-32, 2010.

M. Erdem, E. Akdoğan, M. E. Üreyen, O. Uysal, M. Kaya, C. Irmak, "Yumurta Kabuğu Tozu Katkılanmış Sert Poliüretan Köpükler: Termal İletkenlik, Basma Mukavemeti ve Yanma Davranışlarının İncelenmesi”, Isı Bilimi ve Tekniği Dergisi, 38, 1,83-93, 2018.

M. Yüksel, "Malzeme Bilimleri Serisi Cilt-1", TMMOB Makine Mühendisleri Odasl, Yayın no: MMO/2003/271/2, 21-22, 2003.

P., Keangin, K. Vafai, P. Rattanadecho, "Electromagnetic Field Effects on Biological Materials", International Journal of Heat and Mass Transfer, 65: 389-399, 2013.

R.S. Ramesh, S. Kanakuppi, L.S. Sharanaprabhu, "Study of Hardness and Impact Behaviour of Phenol Formaldehyde Based Wood Plastic Composite", International Journal of Engineering Research \& Technology (IJERT) NCERAME-Conference Proceedings, 167-172, 2015.

T.U. Patro, G. Harikrishnan, A. Misra, D.V. Khakhar, "Formation and Characterization of Polyurethane-Vermiculite Clay Nanocomposite Foams", Polymer Engineering And Science, 1778-1784, 2008. DOI 10.1002/pen.21145

T. Zhang, F. Zhang, S. Dai, Z. Li, B. Wang, H. Quan, Z. Huang, "Polyurethane/organic Vermiculite Composites with Enhanced Mechanical Properties", J. Appl. Polym. Sci. 43219:1-7, 2016. DOI: 10.1002/APP.43219

V. Esenli, "Vermikülit", Madencilik Rehberi, (2012).

Y. Örs, G. Çolakoğlu, İ. Aydın, S. Çolak, "Kayın, Okume ve Kavak Soyma Kaplamalarından Farklı Kombinasyonlarda Üretilen Kontrplakların Bazı Teknik Özelliklerinin Karşılaştııılması", Politeknik Dergisi, 5 (3): 257-265, 2002.

W.J. Seo, J.H. Park, Y.T. Sung, D.H. Hwang, W.N. Kim, S.H. Lee, "Properties of Water-Blown Rigid Polyurethane Foams with Reactivity of Raw Materials", J. Appl. Polym. Sci, 93, 2334-2342, 2004.

Web_1: Maden Tetkik ve Arama Genel Müdürlüğ̈̈, http://www.mta.gov.tr/v3.0/bilgi-merkezi/vermikulit (Erişim tarihi: 17.02.2019)

Web_2: $\quad$ Türk $\quad$ Standartlar1 https://intweb.tse.org.tr/Standard/Standard/Standard.aspx?0811180511151080511041191101040550471051021200881110431131 $\underline{04073083115052068070106121074055102090}$ (Erişim tarihi: 22.02.2019) 